Active and Passive Elec. Comp., June 2004, Vol. 27, pp. 91-94

\title{
SOME NEW FIRST-ORDER ALL-PASS REALIZATIONS USING CCII
}

\author{
KIRAT PAL $^{\mathrm{a}, *}$ and SEEMA RANA ${ }^{\mathrm{b}}$ \\ ${ }^{a}$ Department of Earthquake Engineering, IIT Roorkee, Roorkee-247667, India; \\ ${ }^{\mathrm{b}}$ DAV Centenary Public School, Hardwar - 249404, India
}

(Received 16 February 2003; In final form 21 March 2003)

\begin{abstract}
Some new first-order all-pass filters using a second-generation current conveyor are reported. Two circuits have higher input impedance than reported very recently and use a grounded capacitor. Additionally two more circuits have been reported, one of which has minimum passive and active components and has the facility of single resistance tuning. The other circuit has high input impedance and uses two current conveyors but has one passive component less than the similar circuits reported earlier.
\end{abstract}

Keywords: Active filters; All-pass filters; Current conveyors

\section{INTRODUCTION}

A recent communication has described an all-pass filter using a single current conveyor [1]. The circuit uses a floating capacitor and hence is not suitable for integration. In this paper it has been shown that there exist some more first-order all-pass filters which have higher input impedance than [1] and use a grounded capacitor. As compared to all-pass filters [2-4] most of the presented circuits use fewer components.

\section{PROPOSED CIRCUITS}

The proposed circuits are shown in Figures 1-4. The circuits of Figures 1 and 2 have the same voltage transfer function given by

$$
\frac{V_{o}}{V_{i}}=\frac{1-s C R}{1+s C R}
$$

* Corresponding author. E-mail: kiratfeq@iitr.ernet.in

ISSN 0882-7516 print; ISSN 1563-5031 online (C) 2004 Taylor \& Francis Ltd DOI: $10.1080 / 0882751031000116188$ 


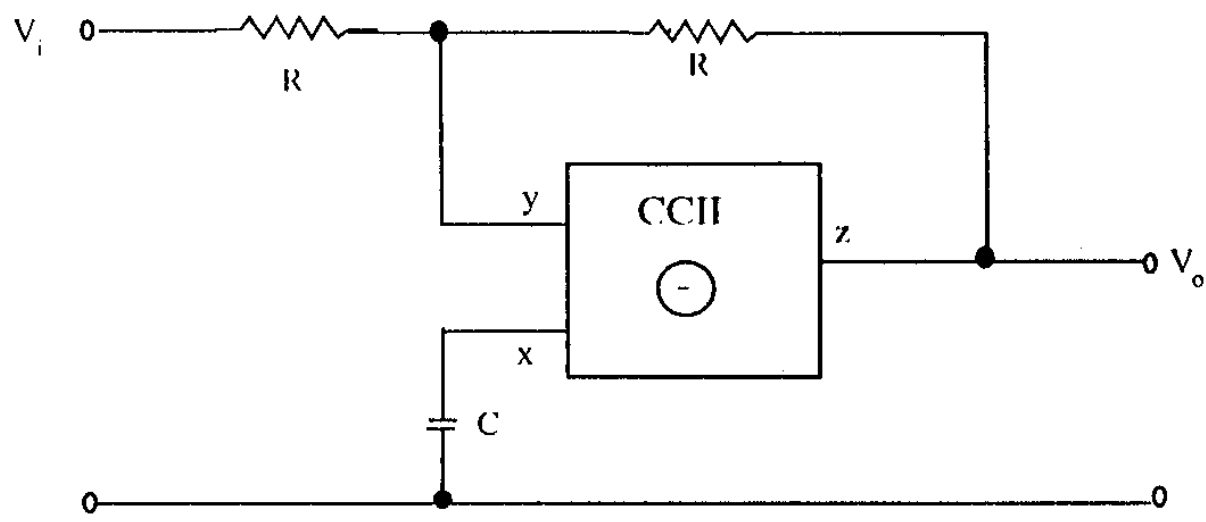

FIGURE 1 A first-order all-pass circuit

The input impedance of these circuits is the same and is given by

$$
Z_{\text {in }}=R+\frac{1}{s C}
$$

The recent circuit [1] has input impedance

$$
Z_{\text {in }}=\frac{R}{2}+\frac{1}{2 s C}
$$

Thus the proposed circuits have input impedance twice that of the recent circuit [1]. In addition, the proposed circuits have the advantage of a grounded capacitor which makes them suitable for integration [5].

The circuit of Figure 3 is derived from the configuration [1] by interchanging $R \& C$ and has the same voltage transfer function. No doubt this configuration uses two capacitors but both are grounded and phase shift can be tuned by varying single resistance ' $R$ ' which is not possible with the circuit [1]. The circuit is ideal for integration.

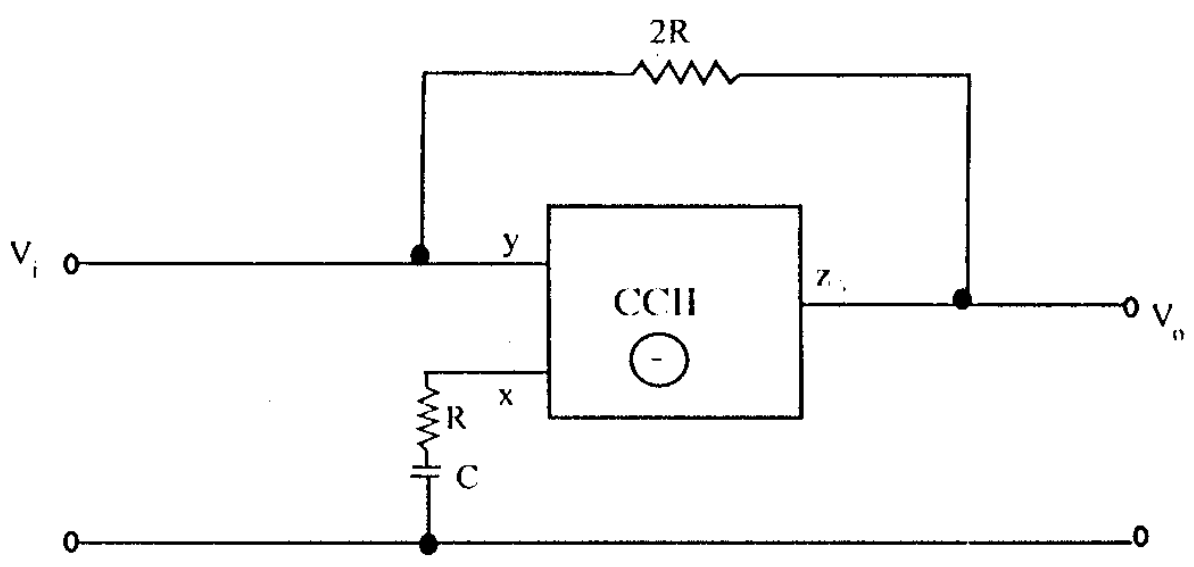

FIGURE 2 Another first-order all-pass circuit 


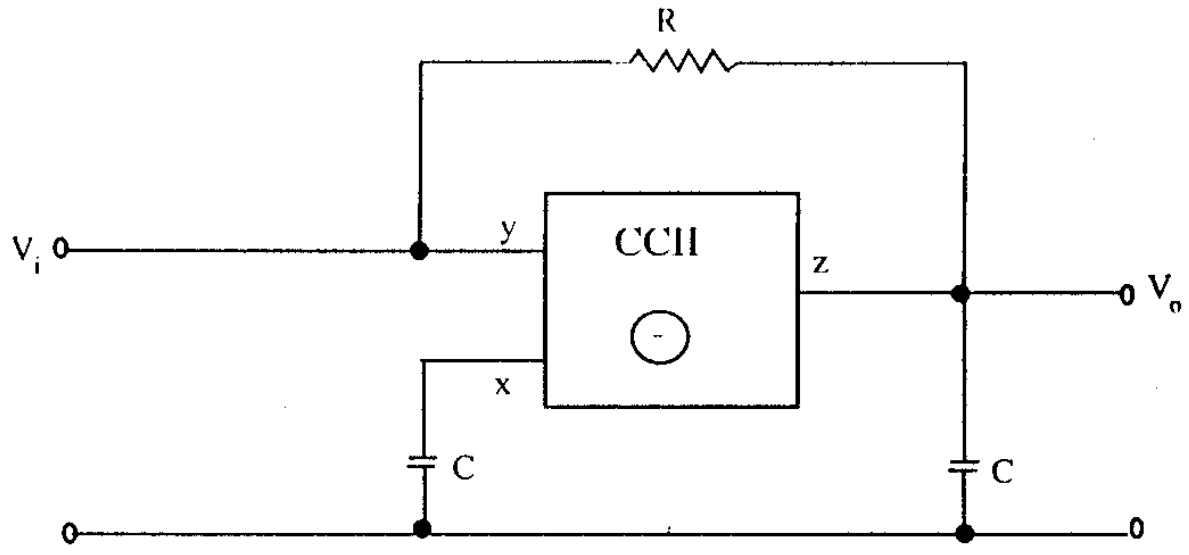

FIGURE 3 A single elements tuned first-order all-pass circuit

The circuit shown in Figure 4 realises a first-order all-pass transfer function of the form

$$
\frac{V_{o}}{V_{i}}=\frac{1-s C R}{1+s C R}
$$

As compared to earlier similar circuits [4] this circuit uses one passive component less and retains all the advantages. A grounded capacitor first-order all-pass realization with high input impedance having equal or fewer components than this has not been achieved yet.

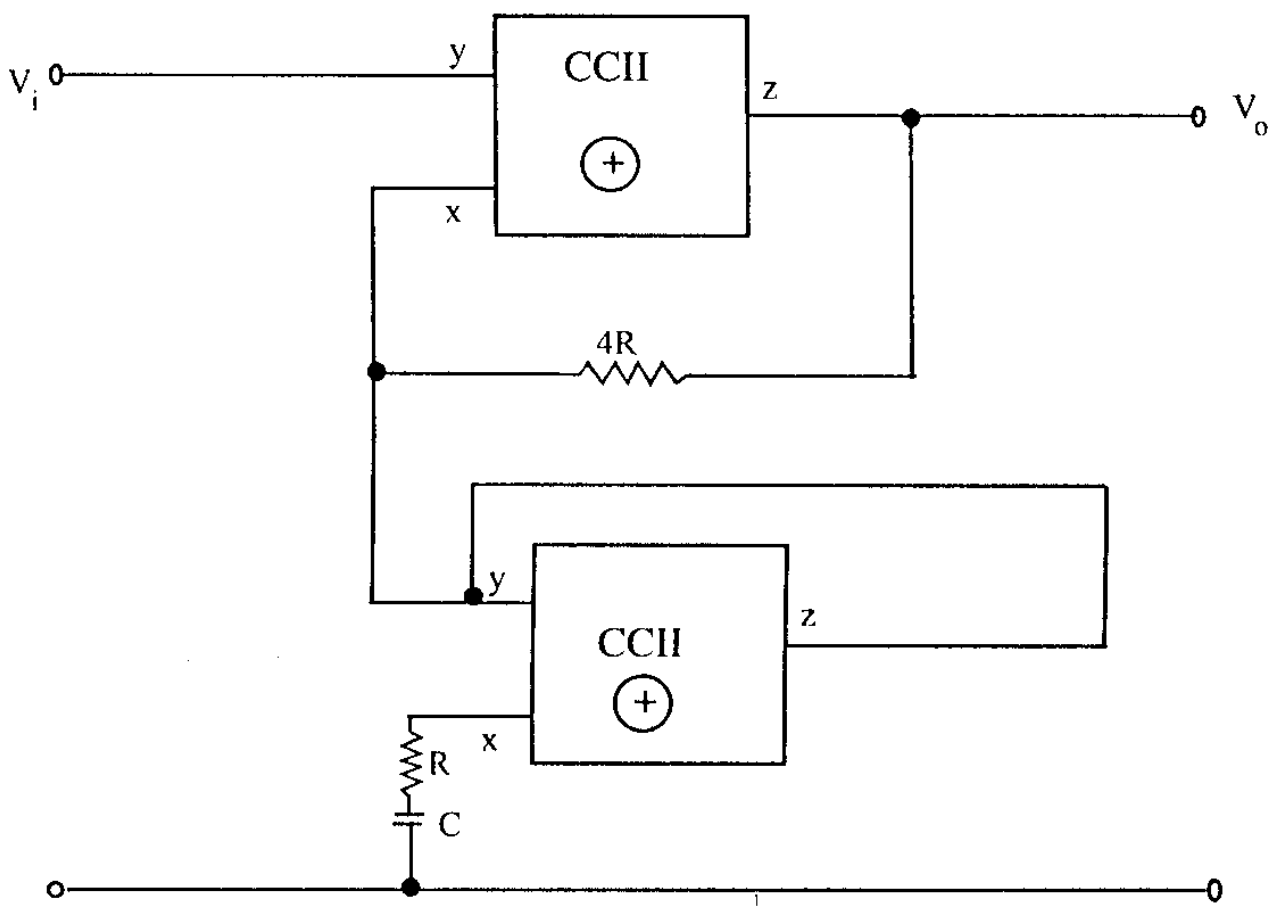

FIGURE 4 A high input impedance first-order all-pass circuit 


\section{CONCLUSIONS}

Some new first-order all-pass circuits having the advantages of using grounded capacitors and higher input impedance than earlier ones have been reported.

\section{References}

[1] Khan, I. A. and Maheshwari, S. (2000). Simple first order all-pass section using a single CCII. International Journal of Electronics, 87, 303-306.

[2] Cicekoglu, O., Kuntman, H. and Berk, S. (1999). All-pass filters using single current conveyor. International Journal of Electronics, 86, 947-955.

[3] Higashimura, M. and Fukui, Y. (1988). Realisation of all-pass networks using a current conveyor. International Journal of Electronics, $\mathbf{6 5}, 249-250$.

[4] Pal, K. (1981). Realisation of current conveyor all-pass networks. International Journal of Electronics, 50, $165-168$.

[5] Bhusan, M. and Newcomb, R. W. (1967). Grounding of capacitors in integrated circuit. Electron. Lett., 3, $148-149$. 

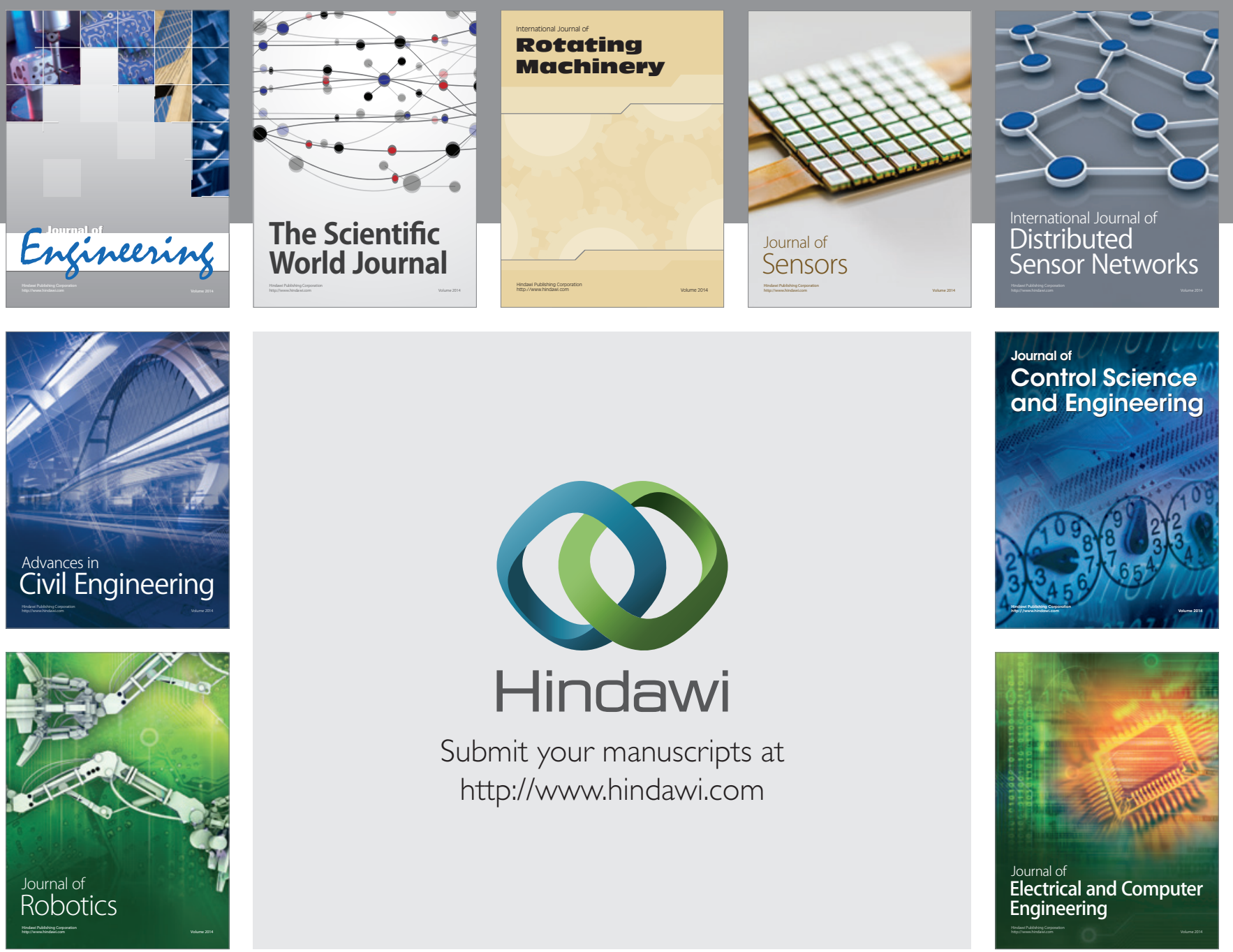

Submit your manuscripts at

http://www.hindawi.com
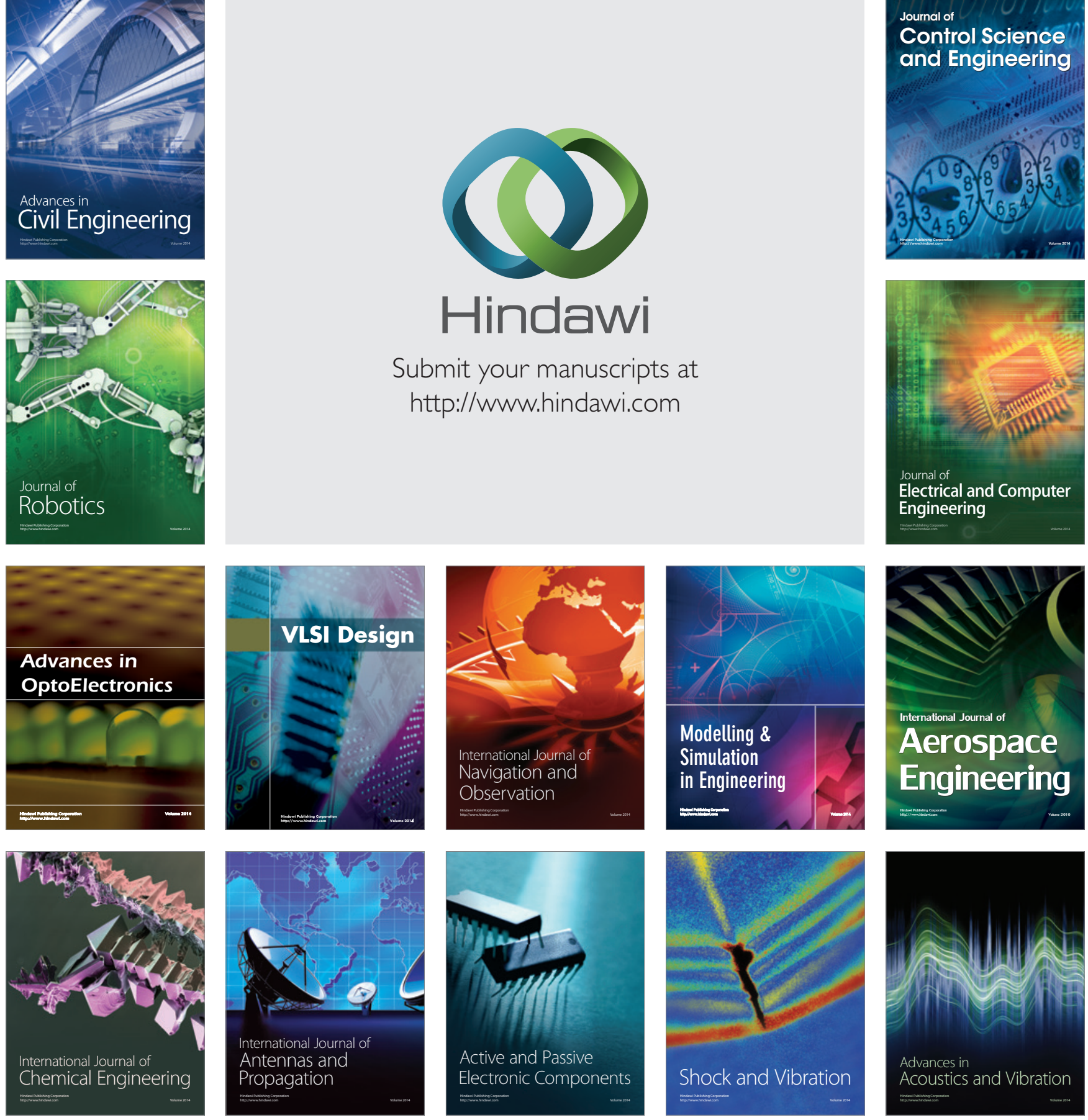